\title{
BLOOD PHYSIOLOGY AND OXYGEN TRANSPORT DURING ACTIVITY IN TWO LIZARDS, VARANUS GOULDII AND SAUROMALUS HISPIDUS
}

\author{
ALBERT F. BENNETT* \\ Department of Zoology, University of Michigan, Ann Arbor, Michigan 48104, U.S.A.
}

(Received 22 Yamuary 1973)

\begin{abstract}
Aspects of blood physiology-hematocrit, oxygen capacity and affinity, lactate content, $\mathrm{pH}$ and composition of blood buffers-were investigated in the lizards Varanus gouldii and Sauromalus hispidus during activity at different temperatures.

2. Although oxygen capacity and affinity, resting $\mathrm{pH}$ and lactate levels, bicarbonate and phosphate concentrations are nearly identical in both species, only Sauromalus sustains a decrease in blood $\mathrm{pH}$ during activity, accompanied by a decrease in oxygen capacity and affinity, high levels of lactate production and exhaustion.

3. Non-carbonic blood buffers prevent a change in blood $\mathrm{pH}$ in Varanus. Lungs of great surface area facilitate exchange of oxygen and carbon dioxide, and Varanus undergoes only moderate lactate generation and remains aerobic during activity.
\end{abstract}

\section{INTRODUCTION}

Most species of reptiles rely principally on anaerobic metabolism for short bursts of rapid activity (Moberly, 1968a, b; Bennett, 1971, 1972b; Wilson, 1971; Bennett \& Licht, 1972; Bennett \& Dawson, 1972, 1973). This anaerobiosis entails high levels of lactate generation and rapid exhaustion; oxygen debt is high and recovery is slow. Reliance on anaerobiosis is necessary since the aerobic capacities of these animals are low: levels of oxygen consumption during rest and activity are much less than those of comparably sized homeotherms (Bartholomew \& Tucker, 1963; Bennett \& Dawson, 1973). The oxygen capacity (Dawson \& Poulson, 1962) and oxygen affinity of the blood (Pough, 1969) are low in comparison to mammalian levels, as are the activities of the aerobic enzymes (Bennett, 1972a). Reptilian activity, therefore, appears to be limited to either slow movements sustainable by limited aerobic capacities or rapid bursts supported anaerobically.

Notable exceptions to the former generalizations are the monitor lizards (genus Varanus). These animals are carnivorous and are highly active predators. They are capable of high-speed pursuit and sustained activity. Aerobic scope is exceptionally high (Bartholomew \& Tucker, 1964; Bennett, 1972b). Resting

* Present address: Department of Zoology, University of California, Berkeley, California 94720. 
levels of oxygen consumption are, however, identical to those of other reptiles of equal size (Bennett, 1972b). Since maintenance costs are equal, it appears that Varamus possesses specific capabilities for sustained oxygen utilization during activity which other lizards lack. An extensive study (Bennett, 1971) was undertaken to determine how varanid lizards are able to function aerobically in contrast to other anacrobic saurians. Previously published portions of that study (Bennett, 1972a, b, 1973) have indicated a lack of specialization in the ventilatory, circulatory or enzymatic systems, suggesting that the blood physiology of varanids may be responsible for their greater oxygen transporting capacity. For instance, a greater blood oxygen capacity or affinity might account for the difference. This study reports measurements of hematocrit and oxygen capacity of the sand goanna, Varanus gouldii, and an iguanid lizard, the spiny chuckwalla, Sauromalus hispidus, animals of equal size (approximately $0.5 \mathrm{~kg}$ ) and thermal preferendum $\left(37-38^{\circ} \mathrm{C}\right)$. The effects of activity on blood $\mathrm{pH}$, lactate content and oxygen affinity are also examined, as well as measurements of the blood buffering capacity and composition of both animals.

\section{MATERIALS AND METHODS}

\section{Experimental animals}

Fifteen adult $S$. hispidus (mean weight, $574 \mathrm{~g}$ ) and ten adult $V$. gouldii (mean weight, $674 \mathrm{~g}$ ) were used in these experiments. Conditions of animal maintenance have been described elsewhere (Bennett, 1972b). Experiments were run on Varanus in FebruaryMarch and on Sauromalus in June-July, the summer active period for both species. All animals were fasted at least 2 days before experimentation.

\section{Hematocrit and oxygen capacity}

Blood samples of approximately $0.3 \mathrm{ml}$ were obtained by ventricular heart puncture from twelve Sauromalus and nine Varanus. Coagulation was prevented by the addition of crystaline sodium heparin, and the samples were thoroughly mixed before analysis. Hematocrit was obtained by centrifuging approximately $50 \mu \mathrm{l}$ of blood for $10 \mathrm{~min}$ at 3000 $\mathrm{rev} / \mathrm{min}$ in flame-sealed heparinized capillary tubes. The percentage of red blood cell volume in the total volume of the sample was recorded as the hematocrit.

The oxygen capacity of the blood was measured by fully oxygenating the sample with air and measuring the total amount of oxygen bound at $25^{\circ} \mathrm{C}$. A $0.25 \mathrm{-ml}$ sample of whole blood was injected into a small glass tonometer $\left(25 \mathrm{~cm}^{3}\right.$ capacity). This was attached to the shaft of a small motor and rotated at $20 \mathrm{rev} / \mathrm{min}$, so that the blood sample formed a thin layer around the inside of the chamber and achieved maximum equilibration with the gas sample. A gas mixture of $95 \%$ air and $5 \%$ carbon dioxide saturated with water vapor $\left(P_{\mathrm{O}_{2}}=145\right.$ torr, $P_{\mathrm{CO}_{2}}=36$ torr, $P_{\mathrm{H}_{1} \mathrm{O}}=24$ torr) was metered into the tonometer at $250 \mathrm{~cm}^{3} /$ $\min$ for $7 \mathrm{~min}$. The tonometer was then sealed, and the sample equilibrated for another $8 \mathrm{~min}$. The entire apparatus was enclosed in a constant-temperature cabinet at $25^{\circ} \mathrm{C}$. At the end of the 15-min equilibration period, the sample was removed and analyzed for oxygen content according to the method of Roughton and Scholander (1943). The oxygen content was expressed as vol $\%\left(\mathrm{~cm}^{3}\right.$ of dry $\mathrm{O}_{2}$ carried in $100 \mathrm{ml}$ of whole blood), corrected to STPD conditions.

\section{Blood lactate content and $p H$}

Blood lactate and $\mathrm{pH}$ werc measured immediately before and after a period of enforced activity. Five or more animals of each species were placed in a constant-temperature 
cabinet overnight and equilibrated to $25,30,35$ or $40^{\circ} \mathrm{C}$. They were then removed individually and $0.35 \mathrm{ml}$ of blood was rapidly obtained by heart puncture. Elapsed time between first handling and sample procurement was less than $30 \mathrm{sec}$; struggling by the animal during this time was minimal.

The $\mathrm{pH}$ of a $0 \cdot 25-\mathrm{ml}$ sample was measured immediately with either a Beckman blood pH microelectrode apparatus and physiological gas analyzer or a Metrohm pH meter equipped with a Leeds and Northrup miniature $\mathrm{pH}$ electrode assembly. The temperature of the electrodes was regulated at the body temperature of the animal by a recirculating water bath. The $\mathrm{pH}$ was recorded to $\pm 0.01 \mathrm{pH}$ unit. This measurement was judged to be the $\mathrm{pH}$ of the blood of the resting animal.

A $0.1-\mathrm{ml}$ sample of blood was precipitated in an equal volume of $3.5 \%$ perchloric acid, mixed and analyzed according to the procedure of Bennett \& Licht (1972). Resulting concentrations of lactate were expressed as $\mathrm{mg} \%$ ( $\mathrm{mg}$ lactate in $100 \mathrm{ml}$ of whole blood).

The lizard was then stimulated for $7 \mathrm{~min}$ by general handling of the legs and tail and by infrequent electrical shocks to the hind limbs. The latter were delivered by a Grass stimulator through safety-pin electrodes. The stimulation was identical to that administered during measurements of aerobic scope, heart rate increment and ventilation volume in previous experiments (see Bennett, 1972b, 1973). Struggling by all animals was intense; Sauromalus, unlike Varamus, often became refractory to further stimulation. Blood samples were collected by heart puncture immediately after activity and 5 and $10 \mathrm{~min}$ post activity. Samples were analyzed for $\mathrm{pH}$ and lactate as described previously. Maximum lactate concentrations and minimum $\mathrm{pH}$ values were always observed immediately after activity or $5 \mathrm{~min}$ post activity.

\section{Blood buffers}

Measurements were made to determine the composition and efficacy of the blood buffering systems of both species of lizards. The bicarbonate-carbonic acid buffer system was assayed by the determination of bicarbonate concentration under standard conditions. This was done manometrically, according to the method outlined by Umbreit et al. (1964). Bicarbonate concentrations were assayed in whole blood samples from 6 Sauromalus and 5 Varanus at $38^{\circ} \mathrm{C}$ in an atmosphere of $5 \%$ carbon dioxide at $95 \%$ air saturated with water vapor $\left(\mathrm{P}_{\mathrm{O}_{2}}=145\right.$ torr, $\mathrm{P}_{\mathrm{CO}}=35$ torr, $\mathrm{P}_{\mathrm{H}_{2} \mathrm{O}}=50$ torr $)$.

A titration curve for all non-carbonic buffers in whole blood was constructed by varying $\mathrm{P}_{\mathrm{CO}}$, of the atmosphere to which the sample was exposed and measuring the resulting $\mathrm{pH}$. A $3.0 \mathrm{ml}$ sample of heparinized blood was obtained for each species by pooling samples from resting individuals. This sample was mixed thoroughly and stored on ice between determinations. The equilibration system and $\mathrm{pH}$ apparatus described previously were utilized. The temperature of the system was regulated at $35^{\circ} \mathrm{C}$. Gas mixtures of varying proportions of $\mathrm{CO}_{2}, \mathrm{O}_{2}$, and $\mathrm{N}_{2}$, saturated with water vapor, were prepared in a 2-liter capacity brass spirometer $\left(\mathrm{P}_{\mathrm{CO}_{2}}=8-175\right.$ torr, $\mathrm{P}_{\mathrm{O}_{2}}=148$ torr, $\mathrm{P}_{\mathrm{N}_{\mathrm{s}}}=385-552$ torr, $\mathrm{P}_{\mathrm{H}_{2} \mathrm{O}}=42$ torr). A $0.3 \mathrm{ml}$ sample of whole blood was placed in the tonometer and equilibrated with the gas mixture as described previously for oxygen capacity measurements. The $\mathrm{pH}$ was measured immediately at the end of the equilibration period.

The phosphate buffers were assayed by determination of the total amount of inorganic phosphate by the spectrophotometric method outlined by Hawk et al. (1947). The increment in the optical density of samples and standard solutions $(2-4 \mathrm{mM} / \mathrm{l}$.) was read on a Beckman DB spectrophotometer at $660 \mathrm{~nm}$.

\section{Oxygen affinity}

The information obtained in the previous experiments was used to determine oxygen affinity of whole blood under conditions of rest and activity at a series of temperatures. In these experiments, a sample of whole blood was exposed to gas mixtures of varying oxygen and carbon dioxide content; the latter was used to regulate the $\mathrm{pH}$ of the blood sample. 
The oxygen content of the sample after equilibration at any given temperature was determined by the Roughton-Scholander method and compared to that of a fully oxygenated sample at $25^{\circ} \mathrm{C}$. The percentage of potential saturation was expressed as a function of $P_{\text {o, }}$

Blood was withdrawn in $2 \cdot 0-\mathrm{ml}$ samples by heart puncture from two lizards of the same species and pooled to provide sufficient blood for analysis. The pooled sample was heparinized, stored in ice water and mixed thoroughly before analysis. The oxygen capacity of this pooled sample was measured at $25^{\circ} \mathrm{C}$ as described previously.

The $\mathrm{pH}$ of the blood sample was regulated at the levels measured in resting and active animals at each temperature. The correct $P_{\mathrm{CO}}$, to establish the desired $\mathrm{pH}$ had to be determined separately for each sample of blood because of varying levels of alkaline reserve between samples. This was facilitated by reference to the titration curve for non-carbonic buffers. The slopes of these curves were nearly identical between samples within a species, although their position on the $P_{\mathrm{CO}}$, axis varied considerably between blood samples. To determine the desired $P_{\mathrm{CO}_{2}}$, the sample was exposed to a known $P_{\mathrm{CO}_{3}}$ and the resulting $\mathrm{pH}$ measured; the desired $P_{\mathrm{CO}}$ could then be estimated by reference to the slope of the titration curve. The sample was then exposed to the predicted $P_{\mathrm{CO}_{3}}$ to check the accuracy of the prediction; $\mathrm{pH}$ was regulated at the desired level $\pm 0.02 \mathrm{pH}$ units. A given $P_{\mathrm{CO}_{2}}$ maintained a constant $\mathrm{pH}$ throughout the entire experiment on a sample. Values of $P_{\mathrm{CO}_{3}}$ required to regulate the desired $\mathrm{pH}$ levels were 25-40 torr and 86-150 torr to simulate rest and activity, respectively, in Sauromalus and 23-32 torr for both conditions in Varanus.

To determine the oxygen saturation of the sample at a given $P_{\mathrm{O}_{1}}$ and $P_{\mathrm{CO}_{2}}$, a gas mixture was made in the spirometer, $0.20 \mathrm{ml}$ of the pooled sample of whole blood was placed in the tonometer, and both were permitted to equilibrate to chamber temperature for $5 \mathrm{~min}$. Equilibration with the gas mixture proceeded as previously described, for a total exposure of $15 \mathrm{~min}$. At the end of this period, the temperature of the sample was measured with a thermocouple connected to a Honeywell recorder. The sample was rapidly withdrawn and analyzed for oxygen content according to the Roughton-Scholander method. The resulting volume was corrected to STPD, and the percentage saturation was determined by dividing the latter volume by the oxygen capacity of the sample. Saturation of each blood sample was measured at six or more different partial pressures of oxygen for cach $\mathrm{pH}$ desired; two separate curves were constructed for each temperature at which the $\mathrm{pH}$ of the blood of the active animal was different from that of the resting animal. At least two equilibration curves were made for each condition and the data were pooled to form composite curves. The variability between curves constructed for different samples under identical conditions was very small; substantially identical curves were obtained from different pooled samples.

\section{Statistics}

All linear regressions reported are the best computed least-squares fit to the data. Mean values are reported with standard errors; 95 per cent confidence limits are used to estimate significance. Difference between mean values was tested by Mann-Whitney $\mathrm{U}$-tests. Mean values for $\mathrm{pH}$ determinations were made by converting data to hydrogen ion concentrations, performing statistical manipulations and reconverting the data to $\mathrm{pH}$ notation.

\section{Hematocrit and oxygen capacity}

The average hematocrit of Sauromalus, $33 \%( \pm 1 \cdot 3)$, is not significantly greater $(P>0 \cdot 1)$ than that of Varanus, $29 \%( \pm 2 \cdot 4)$. Oxygen capacity of the blood, however, is significantly greater $(P<0.02)$ : Sauromalus, 9.7 vol $\%( \pm 0.6)$; Varanus, $8 \cdot 0$ vol $\%( \pm 0 \cdot 5)$. 
Lactate content of the blood

The difference in lactate concentration of the blood of resting Sauromalus, $6.9 \mathrm{mg} \%( \pm 1.0)$, and in resting Varanus, $8.1 \mathrm{mg} \%( \pm 1.9)$, is not significant $(P>0 \cdot 2)$. The resting level of blood lactate is temperature independent.

In active Sauromalus, the maximum lactate concentration in the blood is a direct function of body temperature (Fig. 1) over the range of $25-40^{\circ} \mathrm{C}$ (correlation

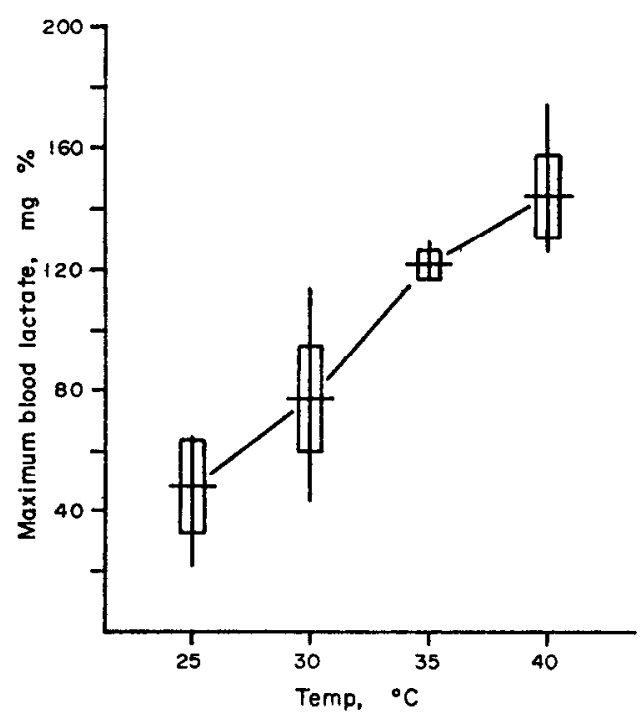

Frg. 1. Maximum lactate concentration in the blood of active $S$. hispidus as a function of body temperature. Horizontal bar indicates mean; vertical rectangle, twice the standard error of the mean; vertical bar, range. The linear regression describing these data is $\mathrm{mg} \%$ lactate $=-117 \cdot 7+6 \cdot 60 T_{\mathrm{b}}$.

coefficient $=0.90$ ). The mean maximum level at $40^{\circ} \mathrm{C}$ is $144 \mathrm{mg} \%$. In contrast, maximum blood lactate in Varamus is temperature independent and considerably lower (Fig. 2): the mean value of all observations is $58.8 \mathrm{mg} \%( \pm 6 \cdot 6)$. Although the utilization of anaerobic metabolism is not significantly different at 25 and $30^{\circ} \mathrm{C}$, Sauromalus relies upon anaerobiosis to a much greater extent than does Varanus at normal activity temperatures $\left(35-40^{\circ} \mathrm{C}\right)$.

\section{Blood pH}

The blood $\mathrm{pH}$ of Saurolamus decreases only slightly with increasing body temperature in resting animals, but decreases greatly in active ones (Fig. 3). The $\mathrm{pH}$ differences in resting and active animals at any given body temperature is temperature dependent. The blood $\mathrm{pH}$ at $25^{\circ} \mathrm{C}$ remains unchanged during activity, but a significant difference appears at $30^{\circ} \mathrm{C}$ and increases at 35 and $40^{\circ} \mathrm{C}$. 
The $\mathrm{pH}$ notation obscures the magnitude of the observed change: at $40^{\circ} \mathrm{C}$, the hydrogen ion concentration of the blood doubles during activity.

The relationship between blood $\mathrm{pH}$ and body temperature in resting Varanus is complex (Fig. 4), suggestive of two temperature plateaus of 7.22 at $25-30^{\circ} \mathrm{C}$ and 7.33 at $35-40^{\circ} \mathrm{C}$. Increasing temperature generally increases resting blood $\mathrm{pH}$. The $\mathrm{pH}$ of the blood does not change during activity in Varanus.

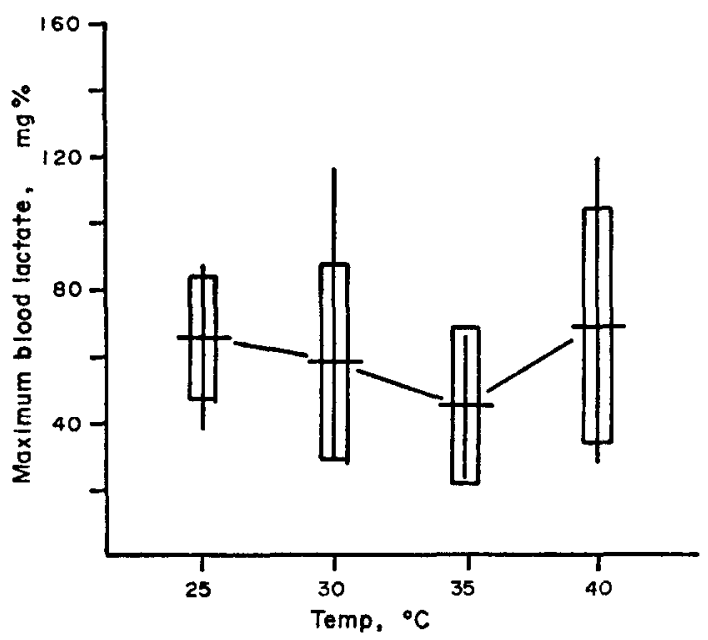

FIG. 2. Maximum lactate concentration in the blood of active $V$. gouldii as a function of body temperature. Symbols as in Fig. 1.

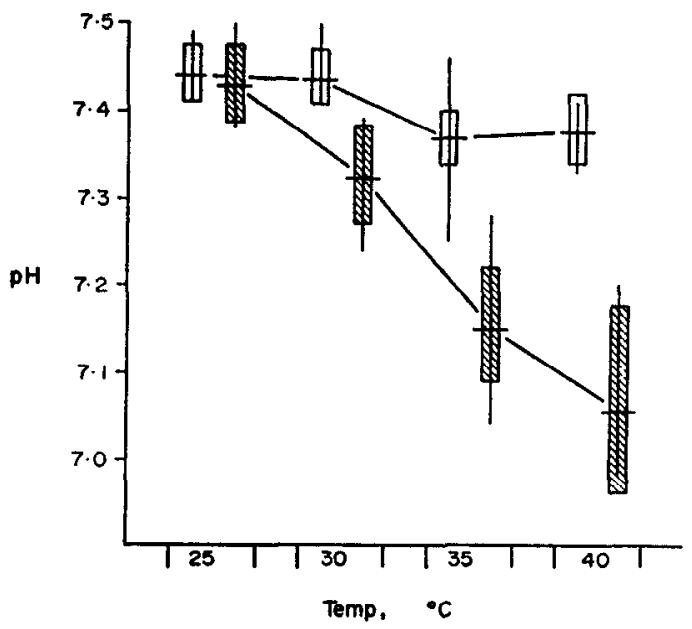

Fig. 3. Blood $\mathrm{pH}$ in resting and active Sauromalus (open and hatched rectangles, respectively). Symbols as in Fig. 1. The linear regressions describing these data are $\mathrm{pH}=7.59-0.0059 T_{\mathrm{b}}$ and $\mathrm{pH}=8.09-0.0263 T_{\mathrm{b}}$ for resting and active animals, respectively. 


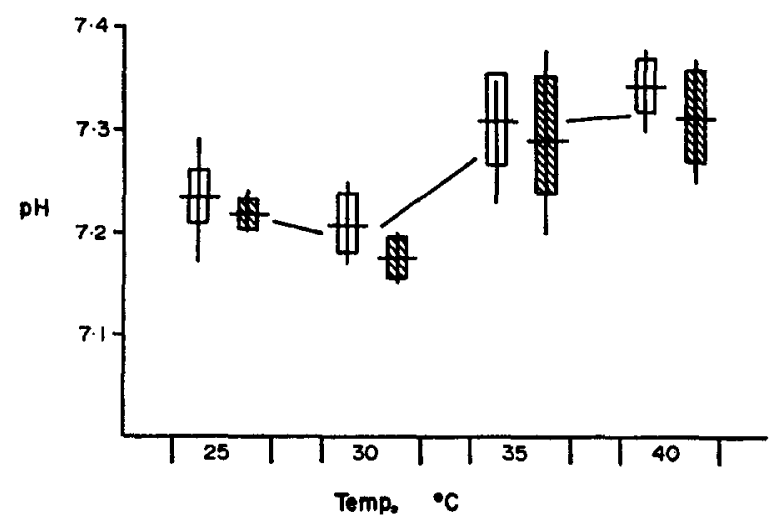

Fig. 4. Blood $\mathrm{pH}$ in resting and active Varanus (open and hatched rectangles, respectively). Symbols as in Fig. 1. The linear regression describing resting $\mathrm{pH}$ is $\mathrm{pH}=7.02+0.0079 T_{\mathrm{b}}$.

Over the normal operating thermal range, $35-40^{\circ} \mathrm{C}$, the blood $\mathrm{pH}$ of resting Sauromalus and Varanus is quite similar (approximately 7.35). Varanid blood is considerably more acidic at $25-30^{\circ} \mathrm{C}$ than that of Sauromalus. During activity at high body temperatures, the blood of Sauromalus reaches a much lower $\mathrm{pH}$ than that of Varanus: 7.06 and $7 \cdot 33$, respectively, at $40^{\circ} \mathrm{C}$.

\section{Blood buffers}

The concentration of bicarbonate in Sauromalus blood, $13.7 \mathrm{mM} / 1 .( \pm 0.8)$, is not significantly different $(P=0.2)$ from that of Varanus, $16.4 \mathrm{mM} / \mathrm{l} .( \pm 1 \cdot 0)$.

The titration curves of non-carbonic blood buffers for both lizards are given in Fig. 5. Siggaard-Andersen (1964) has found that linear approximation represents a satisfactory description of this relationship of $\mathrm{pH}$ as a function of $\log$ $P_{\mathrm{CO}_{z}}$. The non-carbonic buffering strength of Sauromalus blood is $-2.26 \mathrm{log}$ $P_{\mathrm{CO}}$, per unit $\mathrm{pH}$ change. For Varanus, the non-carbonic buffering strength is

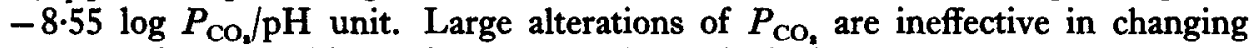
the $\mathrm{pH}$ of varanid blood. The non-carbonic buffering systems of Varanus are, therefore, considerably more effective than those of Sauromalus.

Concentrations of inorganic phosphate in the blood of Sauromalus, $2.05 \mathrm{mM} / 1$. $( \pm 0 \cdot 17)$, and Varanus, $2 \cdot 22 \mathrm{mM} / 1 .( \pm 0 \cdot 16)$ are not significantly different $(P>0 \cdot 2)$. The low levels of inorganic phospate compared to those of bicarbonate and protein support the general conclusion that phosphates contribute little to the overall buffering ability of the blood.

\section{Oxygen affinity}

The relationship between oxygen affinity of whole blood, $\mathrm{pH}$ and temperature is given for Sauromalus and Varanus in Figs. 6 and 7, respectively. Values for the oxygen tension at which the pigment is half-saturated with oxygen $\left(P_{50}\right)$, the maximum saturation achieved and the heme-heme interaction $(n)$ were calculated 


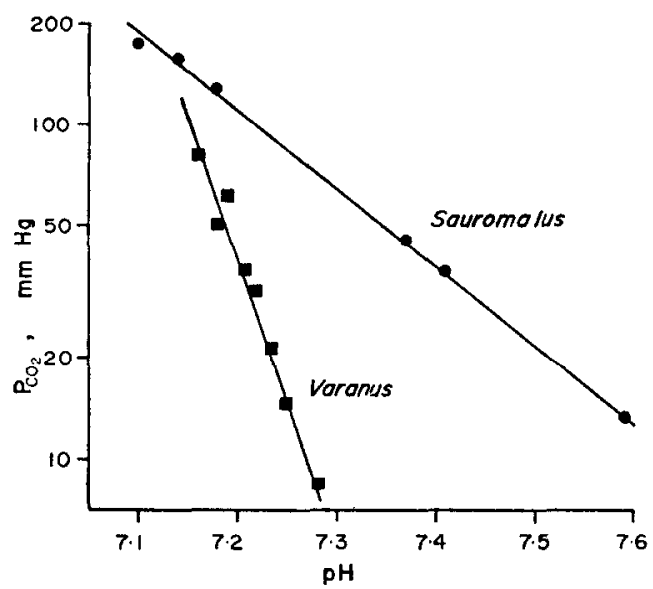

FIg. 5. The pH of whole blood of Sauromalus and Varanus (circles and squares, respectively) at $35^{\circ} \mathrm{C}$ as a function of $P_{\mathrm{CO}}$. Linear descriptions of these data are $\mathrm{pH}=7.78-0.442 \log P_{\mathrm{CO}}$ for Sauromalus and $\mathrm{pH}=7.39-0.117 \log P_{\mathrm{CO}}$ for Varanus.

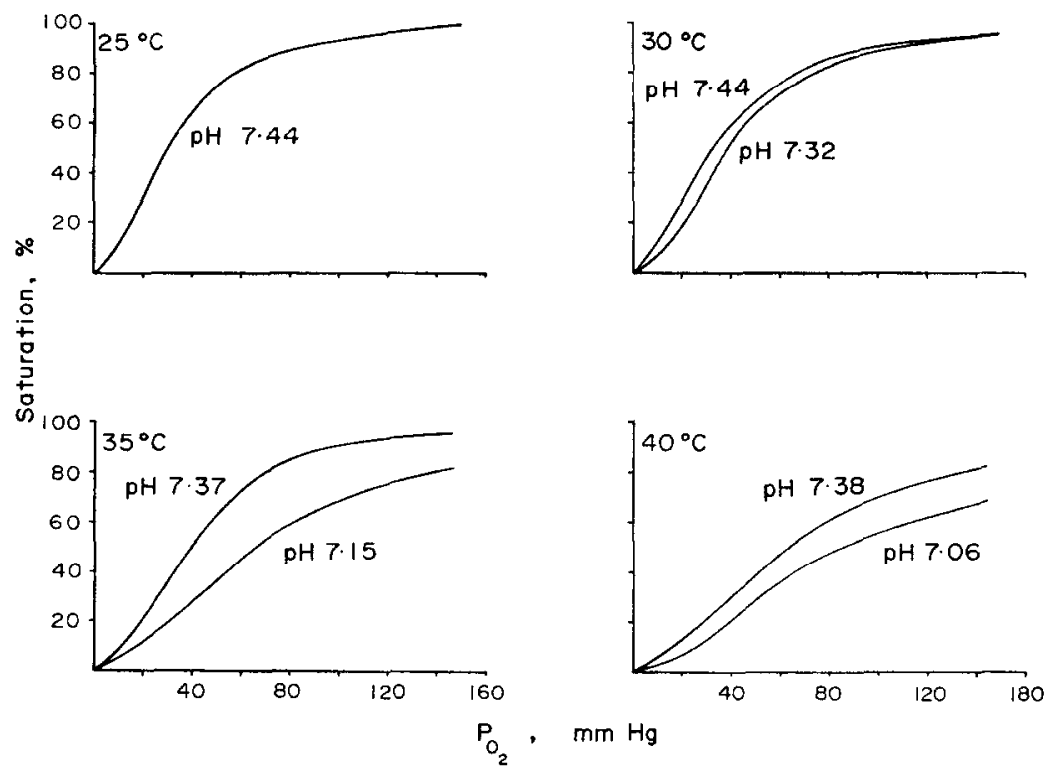

Fig. 6. Oxygen affinity of whole blood as a function of temperature and $\mathrm{pH}$ in S. hispidus.

from these data according to Hill's equation and are reported in Tables 1 and 2.

For Sauromalus, increasing temperature and decreasing $\mathrm{pH}$ during activity drastically decrease oxygen affinity, maximum saturation and heme unit interaction. The Rohr shift as a result of $\mathrm{pH}$ change during activity is quite pronounced, with a mean value of $-0.65 \log P_{50} /$ unit $\mathrm{pH}$. 


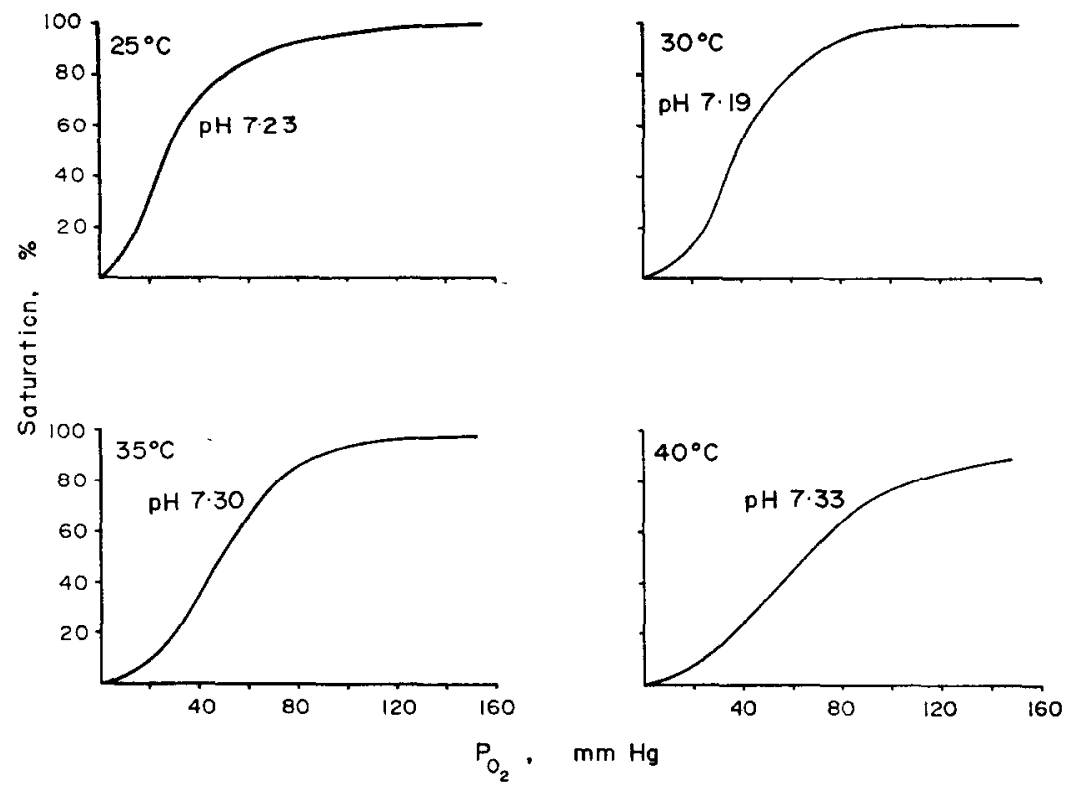

FIG. 7. Oxygen affinity of whole blood as a function of temperature and $\mathrm{pH}$ in $V$. gouldii.

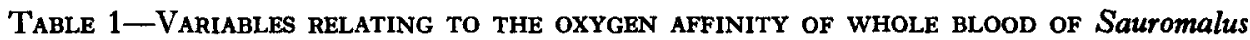
hispidus

\begin{tabular}{|c|c|c|c|c|c|c|c|c|}
\hline \multirow[b]{2}{*}{$\begin{array}{c}T_{\mathrm{b}} \\
\left({ }^{\circ} \mathrm{C}\right)\end{array}$} & \multicolumn{4}{|c|}{ Rest } & \multicolumn{4}{|c|}{ Activity } \\
\hline & $\mathrm{pH}$ & $\begin{array}{c}\text { Max. sat. } \\
(\%)\end{array}$ & $\begin{array}{c}P_{\mathbf{5 0}} \\
\text { (torr) }\end{array}$ & $N$ & $\mathrm{pH}$ & $\begin{array}{l}\text { Max. sat. } \\
(\%)\end{array}$ & $\begin{array}{c}P_{50} \\
\text { (torr) }\end{array}$ & $N$ \\
\hline 25 & $7 \cdot 44$ & 100 & 29 & 1.93 & - & - & - & - \\
\hline 30 & $7 \cdot 44$ & 96 & 32 & $2 \cdot 15$ & $7 \cdot 32$ & 96 & 38 & $2 \cdot 41$ \\
\hline 35 & $7 \cdot 37$ & 96 & 39 & $2 \cdot 37$ & $7 \cdot 15$ & 82 & 64 & 1.92 \\
\hline 40 & $7 \cdot 38$ & 83 & 62 & 1.91 & $7 \cdot 06$ & 69 & 87 & 1.63 \\
\hline
\end{tabular}

TABLE 2-VARIABLes Relating TO THE OXYGEN AFFINITY OF WHOLE BLOOD OF Varamus gouldii

\begin{tabular}{ccccc}
\hline $\begin{array}{c}T_{\mathrm{b}} \\
\left({ }^{\circ} \mathrm{C}\right)\end{array}$ & $\mathrm{pH}$ & $\begin{array}{c}\text { Max. sat. } \\
(\%)\end{array}$ & $\begin{array}{c}\mathrm{P}_{\mathrm{s0}} \\
\text { (torr) }\end{array}$ & $\mathrm{N}$ \\
\hline 25 & $7 \cdot 23$ & 100 & 27 & $2 \cdot 34$ \\
30 & $7 \cdot 19$ & 99 & 37 & $3 \cdot 22$ \\
35 & $7 \cdot 30$ & 97 & 48 & $2 \cdot 87$ \\
40 & $7 \cdot 33$ & 89 & 65 & $2 \cdot 58$ \\
\hline
\end{tabular}


Only one oxygen equilibrium curve was constructed at each temperature for Varanus, since $\mathrm{pH}$ does not change during activity. The oxygen affinity of the blood is very similar to that of resting Sauromalus, in spite of the considerable $\mathrm{pH}$ differential at 25 and $30^{\circ} \mathrm{C}$. Increased temperature also decreases affinity in this species and depresses maximum saturation. The facilitation in oxygen loading or unloading due to heme unit interaction is considerably greater in varanid blood. The maximum saturation observed at ambient $P_{\mathrm{O}}$ is quite similar in both species. The principal differences between the oxygen affinities of the two bloods appear to result from the decrease in blood $\mathrm{pH}$ during activity in Sauromalus.

\section{DISCUSSION}

\section{Hematocrit and oxygen capacity}

'The hematocrits and oxygen capacities measured are very similar to those reported for congeneric species (Varanus griseus, 35\%, Nair, 1955; 32\%, Khalil \& Abdel-Messeih, 1961; Sauromalus obesus, 30\% and 11.8 vol $\%$, Dill et al., $1935)$ and are close to the mean values reported for lizards as a group: $9.8 \mathrm{vol} \%$ (Dawson \& Poulson, 1962). It is clear from these experimental results and those of other workers that the greater aerobic capacities of varanids cannot be explained by a greater blood hemoglobin content or oxygen-carrying capacity than other lizards. Sauromalus has a greater oxygen capacity and a lower aerobic scope. It is possible that such factors as blood viscosity set an upper limit on the hematocrit values and higher oxygen demands must be compensated by other factors.

\section{Blood lactate}

The concentration of blood lactate has been shown to be a good indicator of total anaerobic energy generation during activity (Bennett \& Licht, 1972). The levels of blood lactate indicate that Sauromalus relies on anaerobic metabolism to a far greater extent than Varanus does under identical conditions of activity. The former species often became refractory to stimulation at high body temperatures; Varanus never did and could respond with intense struggling to continuous stimulation for over an hour.

Anaerobic dependence under these conditions of stimulation is strongly temperature dependent in Sauromalus. 'I'his condition contrasts to the thermal independence of maximum blood lactate in Iguana iguana (Moberly, 1968a) and total anaerobic metabolism in several species of small lizards (Bennett \& Licht, 1972). Sauromalus forms excessive $(>100 \mathrm{mg} \%$ ) amounts of lactate at 35 and $40^{\circ} \mathrm{C}$, its normal range of activity temperatures, and Varanus experiences only moderate and sustainable anaerobiosis (see Bennett $\&$ Dawson, 1973, for a review of activity level and blood lactate concentrations). Most reptiles have a great reliance on and tolerance of anaerobic metabolism during rapid or strenuous activity. Varanid lizards appear to constitute a significant exception to this generalization. 
Blood pH

The effect of controlled activity on blood $\mathrm{pH}$ has been poorly investigated in non-mammalian vertebrates. The failure to control or minimize activity is probably responsible for the great variety and range of $\mathrm{pH}$ values reported for reptiles in the literature. Wilson (1971) found a significant decrease in blood $\mathrm{pH}$ during strenuous activity in five species of lizards (agamids and skinks); these decrements are quite similar to those found for Sauromalus in this study. Fish also decrease blood $\mathrm{pH}$ during activity (Auvergnat \& Secondat, 1942; Black et al., 1959; Garey, 1972). Varanus appears exceptional in its ability to prevent acidosis during physical exertion. This regulation has important consequences for the maintenance of aerobiosis during activity.

The response of resting $\mathrm{pH}$ to temperature change in Varanus and Sauromalus in this study does not correspond to that established for other poikilothermous vertebrates by Reeves (1969) and Howell (1970). They have found that blood $\mathrm{pH}$ decreases with increasing body temperature in such a manner that the ratio of hydroxyl to hydrogen ions remains constant. This study indicates that Varanus and Sauromalus maintain a considerable degree of independence of resting $\mathrm{pH}$ and body temperature. The question of $\mathrm{pH}$ or $\mathrm{pOH} / \mathrm{pH}$ regulation in lizards is not completely settled. Further work on this problem should, as Garey (1972) points out, carefully control the effects of activity because of its consequent acidosis in most of these animals.

\section{Blood buffering}

The bicarbonate-carbonic acid system constitutes the principal blood buffer preventing $\mathrm{pH}$ alteration during activity and its consequent generation of lactic acid, according to the following relation:

$\mathrm{H}^{+}$lactate $-+\mathrm{Na}^{+} \mathrm{HCO}_{3}-\rightleftharpoons \mathrm{Na}^{+}$lactate $-+\mathrm{CO}_{2}+\mathrm{H}_{2} \mathrm{O}$. This system, as assayed by the bicarbonate content of the blood, appears no better developed in varanids than in other lizards. The values obtained here are quite similar to those reported for Sauromalus obesus (19.0 mM/1., Dill et al., 1935) and for other lizards (13-21 mM/l., Edwards \& Dill, 1935; Hernandez \& Coulson, 1951; Dessauer, 1952).

The greater buffering ability of varanid blood is manifested in the titration curve for non-carbonic buffers. The buffering value for Varanus, $-8.55 \mathrm{log}$ $P_{\mathrm{Co}} / \mathrm{pH}$, is far greater than that reported for other lizards $(-1.25$ to -5.00 , Dill et al., 1935; Edwards \& Dill, 1935; Verjbenskaya, 1944; Wood \& Moberly, 1970; Wilson, 1971; Bennett \& Wilson, unpublished data), crocodilians (-1.33 to $-2 \cdot 08$, Dill \& Edwards, 1931, 1935) or turtles $(-1.03$ to $-1 \cdot 27$, Southworth \& Redfield, 1926; Wilson, 1939; Verjbenskaya, 1944; Gaumer \& Goodnight, 1957). These buffering values are relatively temperature independent. The intercept of the titration curve is influenced by temperature, recent feeding (alkaline tide) or the addition of non-volatile acids (e.g. lactic acid) (Dill \& Edwards, 1935; Siggaard-Andersen, 1964), but the slope of the curve is thought to reflect the 
concentration and composition of the non-carbonic blood buffers: hemoglobin, plasma proteins, phosphates and non-protein thiol groups.

Since inorganic phosphate levels are low in varanid blood, it might be concluded that the protein buffers are responsible for its greater $\mathrm{pH}$ stability. Hemoglobin levels have been shown to be no higher than in other lizards, but the amino acid composition of varanid hemoglobin and plasma proteins has not been investigated. Another possibility is the presence of high concentrations of non-protein thiol compounds. Fantl (1972) has recently reported extremely high levels of these compounds (over ten times mammalian concentrations) in the plasma of a skink, Tiliqua scincoides, and a turtle, Chelodina longicollis. An investigation into their presence and function in the blood of other reptiles, particularly varanids, is clearly indicated.

\section{Oxygen affinity of the blood}

The oxygen affinity of the blood of Sauromalus and Varanus is nearly identical under similar conditions of $\mathrm{pH}$ and temperature. These relationships suggest that the greater oxygen transporting ability of varanid blood is not the result of increased oxygen affinity of the hemoglobin molecule. It is instead the avoidance of metabolic acidosis during activity, with its consequent depression of carrying capacity, oxygen affinity and heme-heme interaction through the Bohr effect.

It has long been suggested that the low oxygen capacities and affinities and high thermal preferenda of desert lizards might create difficulties in the oxygen transporting function of the blood (Dill, 1938; Prosser \& Brown, 1961; Dawson, 1967). Dill (1938) estimated that arterial blood of $S$. obesus and Heloderma suspectum could reach only 50 and 40 per cent maximum saturation, respectively, at a hypothetical body temperature of $50^{\circ} \mathrm{C}$. The measurements in this study constitute the first demonstration in reptiles of a depression of oxygen capacity at normal activity temperatures and an additional depression due to acidosis during activity. These conditions are analogous to the Root effect in the blood of some fishes, in which the potential capacity of the blood is never realized at low $\mathrm{pH}$ values. Most previous studies on the oxygen affinity of whole reptilian blood (Dill \& Edwards, 1931, 1935; Edwards \& Dill, 1935; Dill et al., 1935; Verjbenskaya, 1944; Pough, 1969; Wood and Moberly, 1970) have assumed that blood exposed to ambient oxygen pressures (140-150 torr) is completely saturated at all body temperatures. This assertion must be accompanied by measurement of the capacity at lower temperatures. If a thermal depression of oxygen capacity does exist, the assumption of complete saturation and the establishment of an oxygen affinity curve on that basis will cause an overestimation of the heme-heme interaction $(n)$, an overestimation of the oxygen affinity at any given $P_{\mathrm{O}}$, and an underestimation of the Bohr shift and thermal dependence. The only other study which has examined the effect of temperature on oxygen affinity in reptiles is that of Greenwald (1971) on the gopher snake, Pituophis melanoleucus affinis. No depression of capacity was found at temperatures up to $35^{\circ} \mathrm{C}$ at $\mathrm{pH} \mathrm{7.4}$. The resting blood $\mathrm{pH}$ and the effect of activity on blood $\mathrm{pH}$ in Pituophis are unknown. 
The oxygen affinities of Sauromalus and Varanus blood are similar to those of other lizards of comparable size. Sufficient data now exist to permit examination of the dependence of oxygen affinity on body size in this group. All reported measurements of saurian oxygen affinity $\left(P_{50}\right)$ of whole blood at $\mathrm{pH} 7 \cdot 4$ or $P_{\mathrm{Co}_{1}}=$ 40 torr at $37-38^{\circ} \mathrm{C}$ (or interpolated to this temperature) are given in Table 3 and Fig. 8. When mean weight values are not reported, body weight is estimated by

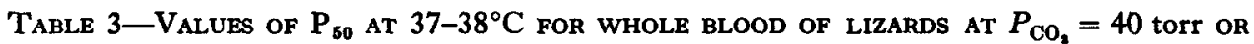
$\mathrm{pH}=7 \cdot 4$

\begin{tabular}{lccl}
\hline \multicolumn{1}{c}{ Species } & $\begin{array}{c}\text { Weight } \\
(\mathbf{g})\end{array}$ & $\begin{array}{c}\mathbf{P}_{50} \\
\text { (torr) }\end{array}$ & \multicolumn{1}{c}{ Reference } \\
\hline & & & \\
Amphibolurus barbatus & 375 & $49 *$ & Bennett \& Wilson (unpublished data) \\
Dipsosaurus dorsalis & 45 & 69 & Pough, 1969 \\
Gerrhonotus multicarinatus & 25 & 72 & Pough, 1969 \\
Heloderma suspectum & $1250 \dagger$ & 50 & Edwards \& Dill, 1935 \\
Iguana iguana & $1300 \dagger$ & 49 & Wood \& Moberly, 1970 \\
Sauromalus hispidus & 574 & 48 & Present study \\
Sauromalus obesus & $210 \dagger$ & 58 & Dill et al., 1935 \\
Sceloporus occidentalis & 11 & 72 & Pough, 1969 \\
Tiliqua rugosa & 500 & $57^{*}$ & Bennett \& Wilson (unpublished data) \\
Uma notata & 30 & 68 & Pough, 1969 \\
Varanus gouldii & 674 & $50^{*}$ & Present study \\
\hline
\end{tabular}

* Estimated assuming Bohr shift of $-0.50 \log P_{50} / \mathrm{pH}$ unit.

+ Estimated from median of weight range.

$\ddagger$ Estimated from standard adult body weight (Pough, 1973).

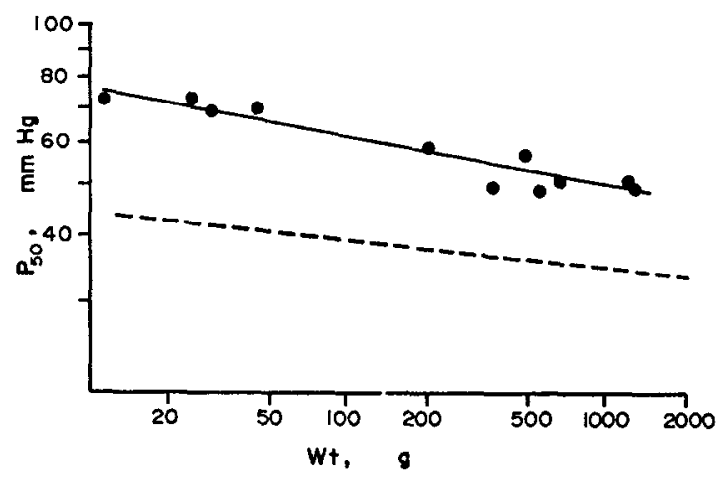

Fig. 8. Relation of $P_{50}$ for whole blood of lizards at $37-38^{\circ} \mathrm{C}$ to body weight. Data are taken from Table 3. Solid regression line is based on Equation (1); dashed line is the regression of Schmidt-Nielsen \& Larimer (1958) for oxygen affinity of mammalian blood [Equation (2)]. 
the median of the weight range or by reference to standard adult body weight (Pough, 1973). The least-squares regression of this relationship is

$$
\begin{aligned}
& \log P_{50}=1.973-0.0936 \log W \\
& (N=11, r=-0.95,95 \% \text { (confidence limits of slope }= \pm 0.024),
\end{aligned}
$$

where $P_{50}$ is measured in $\mathrm{mm} \mathrm{Hg} P_{\mathrm{O}_{3}}$ and $W$ is body weight in $\mathrm{g}$. It can be seen that the affinity of neither Sauromalus nor Varanus blood is exceptionally high or low in comparison to other saurians. Species of smaller body size have a lower blood oxygen affinity and may possess the lowest affinity of any group of vertebrates. Schmidt-Nielsen \& Larimer (1958) have calculated a similar regression for mammalian blood at $37^{\circ} \mathrm{C}$ and $P_{\mathrm{CO}}=40$ torr:

$$
\log P_{50}=1 \cdot 702-0.054 \log W \text {. }
$$

The size dependence of oxygen affinity in lizards is much greater than in mammals, and the affinity itself is much lower: the $P_{50}$ of a $10 \mathrm{~g}$ lizard is 70 per cent greater than that of a $10-\mathrm{g}$ mammal; the differential is 41 per cent for $1-\mathrm{kg}$ animals. It is apparent that oxygen affinity of the blood increased greatly during the evolution of the mammals, in support of increased metabolic demands. Varanid lizards have not adopted this solution to their demands for increased oxygen consumption.

Pough (1969) reported a narrow range of $P_{\mathrm{O}_{3}}$ values (68-72 torr) for five lizard species at their normal activity temperatures. The biological significance of this value is unclear: it may reflect no more than the small size range of the animals investigated. Exclusive of Dipsosaurus in the spring, his data show a similarly narrow range of values of $P_{50}$ at $37.5^{\circ} \mathrm{C}$, irrespective of preferred body temperature. S. hispidus and $V$. gouldii have $P_{50}$ values of 48 and 50 torr, respectively, at their normal activity temperatures.

\section{Effect of activity on oxygen transport}

It is now possible to attempt a composite picture of the function of all these interrelated factors in both lizards during activity. Varanus and Sauromalus are almost identical in most factors affecting oxygen transport and utilization: resting metabolic rate, resting and active ventilation rate, active heart rate, hematocrit, blood oxygen capacity and affinity, resting blood $\mathrm{pH}$ and lactate content, blood bicarbonate and phosphate concentrations and aerobic enzymatic activities in the liver and skeletal muscle. The physiological superiorities of Varanus are few but critical: a complex lung structure with a much greater surface area, excellent non-carbonic blood buffers and high levels of myoglobin in the skeletal muscles (Bennett, 1971, 1972a, b, 1973).

A reasonable hypothesis of the physiological events accompanying activity in Sauromalus is as follows. The energy required in the initial burst of activity is generated by lactate production, as it is in all vertebrates investigated, because of the inherent lag times associated with increasing oxygen transport. Low myoglobin levels delay the transport of oxygen from the blood to the muscle cells. 
The skeletal muscles of Sauromalus have a high activity of phosphofructokinase, the rate-limiting enzyme of glycolysis, doubtless facilitating energy liberation through lactate formation. The lactic acid thus formed and the carbon dioxide formed aerobically diffuse into the blood, where the former is buffered by bicarbonate ions. The bicarbonate-carbonic acid system is a highly efficient buffer, as long as $P_{\mathrm{CO}}$ remains constant or decreases. It is probable, however, that $P_{\mathrm{CO}}$, increases because of aerobically and anaerobically generated $\mathrm{CO}_{2}$. Release of this gas would be hampered by the simple, lightly vascularized lung structure of Sauromalus, as is an increment in oxygen uptake. An increment in $P_{\mathrm{co}}$, would increase the concentration of hydrogen ions in the blood (decrease the $\mathrm{pH}$ ), as is observed during activity. The latter effect greatly decreases the oxygen affinity, oxygen-carrying capacity and heme unit interaction of the blood, which already has a low affinity because of Sauromalus' high thermal preferendum. All these factors considerably hamper oxygen uptake in the lungs and its discharge in the tissues, the latter being further reduced by the low myoglobin content in the muscles. Deprived of an adequate supply of oxygen, Sauromalus must rely on continued anaerobiosis and lactate formation. A cycle is thus established, in which increased reliance on anaerobiosis further decreases the ability to transport oxygen for aerobic metabolism and creates further utilization of anaerobic metabolism. This situation results in an explosive rise in lactate and hydrogen ion concentrations and consequent exhaustion. These factors also are responsible for the high oxygen debt of Sauromalus, since they delay lactate elimination and the re-establishment of muscle phosphagens and oxygen stores.

Varanus escape this anaerobic condition by the efficacy of its non-carbonic blood buffers in preventing a decrease in blood $\mathrm{pH}$ and of its complex lung structure, with its greater ability to release carbon dioxide and to maintain the functioning of its bicarbonate buffers. The lung is also more efficient in oxygen uptake, and high levels of myoglobin, equivalent to those of most mammals, facilitate the rapid transfer of oxygen from the blood into the muscle fibres. Aerobiosis is thus sustained and lactate production is maintained at tolerable levels. These factors likewise minimize the extent and increase the rate of repayment of oxygen debt. The principal features of these models which require further substantiation are the behavior of the $P_{\mathrm{CO}}$ of the blood of both species, the rate of $\mathrm{CO}_{2}$ release, and the arterial-venous differences in oxygen concentration before, during and after activity.

The maintenance cost of the lung structure, blood buffers and myoglobin by varanids cannot be great, since standard metabolism of these animals is no greater than that of other saurians (Bennett, 1972b; Bennett \& Dawson, 1973). The demands for high levels of continuous activity in this group have created adjustments in the basically anaerobic reptilian metabolic pattern to maintain high levels of oxygen acquisition. The oxygen consumption capacities of varanids are, of course, limited: they can reach but only barely exceed those of resting mammals and birds. The latter homeothermic groups are able to utilize far greater amounts of oxygen for a greater level of sustained work. Such a selective 
benefit entails the increased cost of the maintenance of more energetically expensive and complex physiological systems, even under resting conditions.

Acknowledgements-This paper is part of a doctoral dissertation submitted to the Department of Zoology, University of Michigan. Financial support for this study was provided by four N.S.F. Graduate Fellowships (1966-70), N.S.F. Grant GB-3656 to Prof. W. R. Dawson, the Graduate Student Research Fund of the Horace H. Rackham School of Graduate Studies and N.S.F. Grant GB-8212 to Prof. N. G. Hairston for research in Systematic and Evolutionary Biology. I am indebted to the Departments of Zoology at the Universities of Michigan and Western Australia for use of their facilities. In particular, I wish to thank Prof. W. R. Dawson for his assistance and advice throughout my graduate tenure. I thank Prof. P. Licht for critically reading the manuscript and providing many helpful suggestions.

\section{REFERENCES}

Auvergnat R. \& Secondat M. (1942) Retentissement plasmatique de l'exercice musculaire chez la carpe (Cyprinus carpo L.). C. r. Acad. Sci., Paris 215, 92-94.

Bartholomew G. A. \& Tucker V. A. (1963) Control of changes in body temperature, metabolism, and circulation by the agamid lizard, Amphibolurus barbatus. Physiol. Zoöl. 36, 199-218.

Bartholomew G. A. \& Tucker V. A. (1964) Size, body temperature, thermal conductance, oxygen consumption, and heart rate in Australian varanid lizards. Physiol. Zoöl. 37, 341-354.

BeNNETT A. F. (1971) Oxygen transport and energy metabolism in two species of lizards, Sauromalus hispidus and Varanus gouldii. Ph.D. thesis, University of Michigan, Ann Arbor.

BENNETT A. F. (1972a) A comparison of activities of metabolic enzymes in lizards and rats. Comp. Biochem. Physiol. 42B, 637-647.

BENNETT A. F. (1927b) The effect of activity on oxygen consumption, oxygen debt, and heart rate in the lizards Varanus gouldii and Sauromalus hispidus. $\mathcal{F}$. comp. Physiol. 79, 259-280.

BENNETT A. F. (1973) Ventilation in two species of lizards during rest and activity. Comp. Biochem. Physiol. 46A, 653-671.

Bennett A. F. \& Dawson W. R. (1972) Aerobic and anaerobic metabolism during activity in the lizard Dipsosaurus dorsalis. F. comp. Physiol. 81, 289-299.

Bennett A. F. \& Dawson W. R. (1973) Metabolism. In Biology of the Reptilia (Edited by Gans C.), Physiology A, Vol. 5. Academic Press, New York. (In press.)

Bennett A. F. \& Licht P. (1972) Anaerobic metabolism during activity in lizards. $\mathscr{f}$. comp. Physiol. 81, 277-288.

Black E. C., Chiu W., Forbes F. D. \& Hanslip A. (1959) Changes in pH, carbonate and lactate of the blood of yearling Kamloops trout, Salmo gairdneri, during and following severe muscular activity. F. Fish. Res. Bd Can. 16, 391-402.

Dawson W. R. (1967) Interspecific variation in physiological responses of lizards to temperature. In Lizard Ecology: $A$ Symposium (Edited by Milstead W. W.), pp. 230-257. University of Missouri Press, Columbia.

Dawson W. R. \& Poulson T. L. (1962) Oxygen capacity of lizard bloods. Am. Midl. Nat. 68, 154-164.

Dessauer H. C. (1952) Biochemical studies on the lizard, Anolis carolinensis. Proc. Soc. exp. Biol. Med. 80, 742-744.

Dill D. B. (1938) Life, Heat, and Altitude: Physiological Effects of Hot Climates and Greot Heights. Harvard University Press, Cambridge. 
Dill D. B. \& Edwards H. T. (1931) Physicochemical properties of crocodile blood (Crocodilus acutus, Cuvier). Э. biol. Chem. 90, 515-530.

Dill D. B. \& Edwards H. T. (1935) Properties of reptilian blood-IV. The alligator (Alligator mississippiensis Daudin). J. cell. comp. Physiol. 6, 243-254.

Dill D. B., Edwards, H. T., Bock A. V. \& TalbotT H. H. (1935) Properties of reptilian blood-III. The chuckwalla (Sauromalus obesus Baird). F. cell. comp. Physiol. 6, 37-42.

Edwards H. T. \& Dill D. B. (1935) Properties of reptilian blood-II. The gila monster (Heloderma suspectum Cope). F. cell. comp. Physiol. 6, 21-35.

FANTL P. (1972) Evolutionary trends in plasma mercaptalbumin composition. Comp. Biochem. Physiol. 42B, 403-408.

Garey W. F. (1972) Determination of the normal blood pH of fishes. Respir. Physiol. 14, 180-182.

Gaumer A. E. H. \& Goodnight C. J. (1957) Some aspects of the hematology of turtles as related to their activity. Am. Midl. Nat. 58, 332-340.

GreENWALd O. E. (1971) Effect of temperature on the oxygenation of gopher snake blood. Comp. Biochem. Physiol. 40A, 865-870.

Hawk P. B., Osec B. L. \& Summerson W. H. (1947) Practical Physiological Chemistry, 12th Edn. Blakiston Co., Philadelphia.

Hernandez T. \& Coulson R. A. (1951) Biochemical studies on the iguana. Proc. Soc. exp. Biol. Med. 76, 175-177.

Howel. B. J. (1970) Acid-base balance in transition from water breathing to air breathing. Fedn Proc. Fedn Am. Socs exp. Biol. 29, 1130-1134.

Khalil F. \& Abdel-Messein G. (1961) Effect of water deficit and water excess on the composition of blood of Varanus griseus Daud. $Z$. vergl. Physiol. 45, 82-87.

MoBERLY W. R. (1968a) The metabolic responses of the common iguana, Iguana iguana, to activity under restraint. Comp. Biochem. Physiol. 27, 1-20.

Moberly W. R. (1968b) The metabolic responses of the common iguana, Iguana iguana, to walking and diving. Comp. Biochem. Physiol. 27, 21-32.

NaIR S. G. (1955) The oxyphoric capacity of the blood of some reptiles and mammals. F. Anim. Morphol. Physiol. 1, 48-54.

Pough F. H. (1969) Environmental adaptations in the blood of lizards. Comp. Biochem. Physiol. 31, 885-901.

Pough F. H. (1973) Lizard energetics and diet. Ecology. (In press.)

Prosser C. L. \& Brown F. A., Jr. (1961) Comparative Animal Physiology, 2nd Edn. W. B. Saunders, Philadelphia.

REEvEs R. B. (1969) Role of body temperature in determining the acid-base state in vertebrates. Fedn Proc. Fedn. Am. Socs exp. Biol. 28, 1204-1208.

Roughton F. J. W. \& Scholander P. R. (1943) Micro gasometric estimation of the blood gases-I. Oxygen. F. biol. Chem. 148, 541-550.

SChMidT-NIELSEN K. \& LARIMER J. L. (1958) Oxygen dissociation curves of mammalian blood in relation to body size. Am. F. Physiol. 195, 424-428.

Siggaard-Andersen D. (1964) The Acid-base Status of the Blood, 2nd Edn. Williams \& Wilkins, Baltimore.

Southworth F. C., JR. \& Redfieln A. C. (1926) The transport of gas by the blood of the turtle. F. gen. Physiol. 9, 387-403.

UMbreit W. W., BurRis R. H. \& Stauffer J. F. (1964) Manometric Techniques: A Manual Describing Methods Applicable to the Study of Tissue Metabolism, 4th Edn. Burgess, Minneapolis.

VerjBenskaya N. A. (1944) Comparative study of the respiratory function of reptilian blood. Akad. Nauk SSSR (Leningrad), Izvest., Ser. Biol. 1944, 156-171.

Wilson J. W. (1939) Some physiological properties of reptilian blood. F. cell. comp. Physiol. $13,315-326$. 
WILSON K. J. (1971) The relationships of activity, energy, metabolism, and body temperature in four species of lizards. Ph.D. thesis, Monash University, Clayton.

Wood S. C. \& MoBerLy W. R. (1970) Influence of temperature on the respiratory properties of iguana blood. Respir. Physiol. 10, 20-29.

Key Word Index-Activity; aerobic scope; anaerobiosis; bicarbonate; blood; blood buffering; hematocrit; hemoglobin; lactate; lizard; oxygen affinity; oxygen capacity; pH; phosphate; reptile; Sauromalus; temperature; Varanus. 